\title{
Braquetes autoligados: eficiência x evidências científicas
}

\author{
Renata Castro*
}

\section{INTRODUÇÃO}

Os braquetes autoligados têm sido apresentados como um diferencial para o ortodontista clínico que procura se desdobrar na tentativa de oferecer um tratamento de excelência no menor tempo possível e com número mínimo de consultas. No entanto, a quantidade de informações propiciadas por verdades estabelecidas e não comprovadas a longo prazo cresce a uma velocidade vertiginosa.

Contrariamente ao que muitos pensam, os braquetes autoligados não representam um desenvolvimento recente e revolucionário, pois, desde 1935, Russel $^{12,20}$ descreveu na literatura que o uso de amarrilhos para fixação do arco era dispensável na Ortodontia. Nesse sistema, o arco era fixado e pressionado dentro da canaleta dos braquetes Edgewise por um parafuso. Sendo assim, há mais de 70 anos, esse conceito já fazia parte do arsenal ortodôntico, mas, em função do alto custo e fragilidade das peças devido às limitações de fabricação ${ }^{21}$, não se popularizou como provavelmente mereceria. Somente em 1972, surgiu outro dispositivo, idealizado por Wildman ${ }^{25}$ e chamado Edgelok (Ormco Corp., EUA), que apresentava uma tampa por vestibular para fechar a canaleta do braquete $\mathrm{e}^{5,12,25}$.

$\mathrm{Na}$ década de 80 , novos sistemas surgiram. O Mobil-lock (Forestadent, Alemanha) precisava de um instrumento rotatório para abrir e fechar a canaleta, porém, assim como o Edgelok, esse sistema apresentava controle de rotação muito pobre ${ }^{12}$. O Speed (Strite Industries Ltd., Canadá) - com um design mais estético, significativamente menor e, consequentemente, com distância interbraquetes maior - apresentava uma redução no acúmulo de alimentos e uma propaganda forte de que esse braquete causaria menor atrito durante a movimentação ortodôntica ${ }^{6}$. Esse sistema se diferenciava dos anteriores por apresentar uma tampa que deslizava no sentido vertical para fechamento da canaleta. A característica ímpar dessa tampa é ter sido confeccionada, originalmente, com aço inoxidável e, hoje em dia, ela apresenta uma liga de níquel-titânio fina e resiliente, que a torna extremamente flexível $^{6}$. Alguns estudos ${ }^{4,19}$ salientam a facilidade de fechamento das tampas dos braquetes, ocasionando redução do tempo de até quatro vezes em relação aos sistemas convencionais com elásticos.

Logo depois do Speed, surgiu um braquete de forma cilindrica, o Activa ${ }^{13}$ ("A" Company Orthodontics, EUA), com o propósito de acelerar o processo de inserção do fio dentro da canaleta; no entanto, a comercialização desses braquetes foi descontinuada devido à facilidade com que os pacientes abriam sua tampa ${ }^{4,8,12}$. Nota-se que algumas das dificuldades iniciais foram contornadas, embora nenhum desses sistemas, com exceção do Speed, tenha se mantido em evidência até os dias de hoje ${ }^{6}$.

Na década de 90, surgiu o braquete Time (Adenta $\mathrm{GmbH}$, Alemanha) que se assemelhava ao Speed na aparência e na maneira ativa de atuação ${ }^{8,12,24}$. Em seguida, a American Orthodontics (EUA) lançou o braquete com tampa ativa chamado Sigma ${ }^{9}$, concomitantemente com o lançamento dos sistemas passivos Damon SL I (Ormco Corp., EUA) 3,9,10

\footnotetext{
* Mestre e doutora em Ortodontia pela Faculdade de Odontologia de Bauru - Universidade de São Paulo (FOB-USP). Professora do programa de pós-graduação em Odontologia, área de concentração Ortodontia, da Universidade Metodista de São Paulo (Umesp-SP).
} 
e, mais tarde, em 1999, o Damon SL II ${ }^{3}$. Ambos apresentam uma tampa lisa e retangular que desliza entre as aletas. A justificativa desses novos sistemas era que o seu desenho permitiria um rápido nivelamento, devido ao fato dos dentes deslizarem por um caminho de pouca, ou nenhuma, fricção entre o braquete e a canaleta ${ }^{13,21}$. No sistema Damon SL I havia muitas quebras da trava deslizante, já no sistema Damon SL II houve uma melhora nessa imperfeição, diminuindo o número de quebras $^{12}$. A "A" Company lançou, em 1998, mais um braquete passivo, chamado Twin-lock ${ }^{8}$, semelhante ao Edgewise geminado, porém com tampa que se move no sentido oclusal com o auxílio de um instrumento universal ${ }^{3,12}$.

No início do século XXI, surgiu o Oyster (Gestenco International AB, Suécia), o primeiro sistema autoligado estético, feito de fibra de vidro reforçada por um polímero, dando transparência ao braquete. A tampa fecha sobre a canaleta no sentido cervico-oclusal, funcionando de forma ativa, porém, caso se queira, pode-se removê-la e o braquete funciona como um sistema tradicional, sendo necessária a utilização de amarrilhos metálicos ou elásticos para manter o fio dentro da canaleta ${ }^{8,12}$. Mas se ele funciona como um sistema tradicional, por que usá-lo, e não um braquete estético convencional? Faltam estudos que comparem a eficiência do braquete estético convencional com o autoligado, e essa dúvida tira o sossego até mesmo dos profissionais mais experientes. Em seguida, a GAC Internacional (EUA) desenvolveu o sistema ativo In-Ovation $\mathrm{R}^{1,12}$, que usa fios de menor calibre durante o alinhamento e o nivelamento para deixar os braquetes, em teoria, mais passivos, pois a tampa está distante do fio dentro da canaleta. À medida que se aumenta o calibre do arco e passa-se a usar fios retangulares, o contato justo do fio com a tampa o torna ativo. Em 2004, surgiu o Damon III, considerado semiestético, com um mecanismo fácil e seguro para abertura e fechamento da trava; entretanto, ele apresentava três problemas significativos: descolagem frequente, separação do metal com a porcelana, e fratura da aleta ${ }^{12}$. Ressalta-se, ainda, que, se um paciente almeja um braquete estético associado à ligadura elástica também esteticamente aceitável, a escolha do Damon III não seria a melhor opção.

Em 2006, surgiu o In-Ovation C (GAC International, EUA) ${ }^{1}$, também autoligado ativo. Nesse mesmo período, o sistema Damon lançou o Damon $\mathrm{MX}^{7,12}$, o qual dividia o tratamento em quatro fases: fase 1 - arco redondo de alta tecnologia (0,013"; 0,014" ou 0,016" Copper NiTi); fase 2 arco retangular de alta tecnologia $(0,014$ " $\mathrm{x} 0,025$ "; $0,016^{\prime \prime}$ x 0,025"; $0,018 "$ x 0,025"; 0,019" x 0,025" Copper NiTi); fase 3 - maior mecânica $(0,019 "$ x 0,025 " retangular aço); e fase 4 - finalização e detalhamento (continuação do arco de aço ou 0,019" x 0,025" TMA) ${ }^{7,12}$. Em seguida, a Forestadent (Alemanha) apresentou o aparelho autoligado ativo chamado Quick ${ }^{12}$; a Ortho Organizers (EUA) lançou o sistema passivo Carriere LX, com uma base microrretentiva e menos volumoso; e por último a $3 \mathrm{M}$ Unitek (EUA), com a inovação do sistema autoligado, apresentando o SmartClip ${ }^{\mathrm{TM}}$ Self-ligating. Esse sistema ${ }^{22,23}$ se diferencia de todos os outros por conter dois clipes na lateral para prender o fio dentro da canaleta. Vale lembrar que o sistema SmartClip segue os conceitos da biomecânica de deslizamento do aparelho ortodôntico MBT Versátil, com aplicação de forças leves e uso do fio retangular de último calibre 0,019 " $\mathrm{x}$ 0,025 " na canaleta 0,022 " x 0,028 ", além de preconizar uma sequência de fios semelhante à do tratamento convencional, com pequena mudança na fase do alinhamento e nivelamento para fios de nitinol superlásticos, em relação aos de nitinol ${ }^{22}$. O SmartClip apresenta-se com o formato romboide e com ângulo inserido na forma do braquete, o que favorece o posicionamento dos braquetes, pois o profissional pode usar as bordas incisais, as bordas laterais e o eixo vestibular como referência de posicionamento na face vestibular dos dentes ${ }^{12,22,23}$.

Em 2008, no catálogo da Ormco (www.ormco.com), surgiu o Damon Q. No catálogo da 3M 
Unitek (www.3munitek.com.br), o Clarity ${ }^{\mathrm{TM}}$ SL (braquetes cerâmicos autoligados, de aletas duplas, com a estética dos braquetes cerâmicos Clarity); e no da Aditek (www.aditek.com.br) o Easy Clip. Todos esses recentes lançamentos têm como característica comum o sistema passivo.

Atualmente, quase todos os fabricantes de braquetes ortodônticos desenvolveram, ou estão desenvolvendo, seus sistemas. Sendo assim, surge a pergunta: Qual sistema autoligado é mais eficiente quando leva-se em conta a relação custo-benefício? O braquete autoligado é apenas uma moda passageira na Ortodontia? O custo adicional justifica a inserção desse sistema em todos os casos a serem tratados numa clínica particular?

Em 2007, Miles ${ }^{16}$ comparou a taxa de retração em massa com a mecânica de deslizamento entre os braquetes SmartClip e braquetes Twin convencionais e concluiu que não houve diferença na taxa de retração entre esses braquetes. Nesse mesmo ano, um estudo prospectivo com 59 pacientes $^{17}$ comparou o tempo de tratamento para correção do apinhamento inferior com braquetes convencionais e com Damon II, bem como as distâncias intercaninos e intermolares. O período avaliado foi do início (T1) ao final do nivelamento (T2). A conclusão principal foi que não houve diferença no tempo de tratamento para correção do apinhamento inferior entre os braquetes Damon II e os convencionais. Além disso, a vestibularização dos incisivos inferiores foi a mesma em ambos os grupos e no Damon II a distância intermolares foi maior.

Em 2008, Araújo ${ }^{2}$ avaliou as inclinações das coroas dentárias dos dentes anteriores superiores e inferiores decorrentes do tratamento sem extrações, com braquetes autoligados (Damon II ${ }^{\mathrm{TM}}$ ), e comparou aos valores da prescrição citada pelo fabricante, por meio da tomografia computadorizada. A amostra foi composta por 10 pacientes ( 6 homens e 4 mulheres) que se encontravam na fase da dentadura permanente e com má oclusão inicial de Classe I bilateral. Também como critérios de seleção, todos os pacientes deveriam apresentar ausências de problemas transversais, anteroposteriores ou verticais severos que contraindicassem tratamentos ortodônticos convencionais. $\mathrm{A}_{\text {autora }}{ }^{2}$ concluiu que os dentes apresentaram valores de inclinação diferentes da prescrição, tanto no início (T1) quanto no final do tratamento ortodôntico (T2), após a inserção do último fio de nivelamento 0,019 " x 0,025 " de aço inoxidável, denotando a incapacidade dessse fio em reproduzir os torques indicados na prescrição padrão.

Ao aumentar essa amostra de 10 (ARAÚJO², 2008) para 18 pacientes, Kochenborger ${ }^{14}$, em 2009, avaliou as alterações dentárias dos dentes anteriores e as dimensões transversais dos arcos superior e inferior, bem como as alterações do perfil facial decorrentes do tratamento ortodôntico com braquetes autoligados Damon II $^{\mathrm{TM}}$. Como conclusão, o autor ${ }^{14}$ relatou que esse sistema não promoveu alteração na inclinação vestibulolingual dos incisivos centrais superiores, porém aumentou a inclinação vestibular dos incisivos centrais inferiores. Não houve alteração do perfil facial, mas, em compensação, houve um aumento significativo na dimensão transversal da maxila e da mandíbula, por meio de inclinação de coroa. Vale lembrar que, o sistema Damon ${ }^{10}$ preconiza o uso de fios termoativados, visando promover expansão progressiva do arco dentário no tratamento de más oclusões com apinhamentos.

Em um estudo in vitro ${ }^{15}$ de comparação do atrito em braquetes metálicos e estéticos convencionais e autoligados, foram utilizados 120 braquetes de 6 marcas comerciais, sendo 20 braquetes de cada marca. Para os ensaios laboratoriais, foram colados dois braquetes de cada marca comercial em um placa metálica, com uma angulação de zero e três graus entre os braquetes. Foram empregados os fios retangulares de aço inoxidável 0,017" x 0,025"; 0,019 " x 0,025" e 0,021" x 0,025" em uma máquina de ensaios universal Instron. Os resultados demonstraram que, na angulação de zero grau, os braquetes autoligados apresentaram menor atrito, em relação aos convencionais, em todos os fios avaliados, 
sendo que o braquete Clarity autoligado promoveu menor atrito que o Damon, exceto no fio 0,021 " $\mathrm{x}$ 0,025 ". Já na angulação de três graus, observou-se resultados semelhantes dos braquetes autoligados em relação aos convencionais. Pode-se concluir que a angulação entre os braquetes aumenta consideravelmente o atrito, fazendo com que a composição dos braquetes convencionais influencie de forma mais significativa o atrito.

Estudo recente ${ }^{18}$, com 14 pacientes, avaliou a retenção de placa bacteriana durante o tratamento com braquetes convencionais amarrados com elastômeros e autoligados (In-Ovation R/ Mini-Ovation, GAC) e conclui-se que pacientes com braquetes autoligados têm menores índices de placa bacteriana do que aqueles que recebem braquetes convencionais.

Por sua vez, uma revisão sistemática de $2009^{11}$ analisou a quantidade de resistência friccional expressa entre braquetes convencionais e autoligados in vitro. Para tanto, foi feita uma busca, ilimitada, em bases de dados (Medline, PubMed, Embase, Cochrane Library e Web of Science) e os artigos sobre fricção entre braquetes convencionais e autoligados foram selecionados e revisados. Além disso, foram checadas as referências bibliográficas de todos os artigos, para identificar alguma pesquisa que não houvesse sido capturada na busca eletrônica. Feita a busca, foram eliminados os resumos de artigos descritivos, editoriais, cartas, estudos in vivo ou aqueles que não estivessem avaliando braquetes autoligados ou que estivessem estudando outras propriedades dos braquetes que não a friç̧ão. Ao final, 70 artigos foram selecionados pela busca eletrônica e 3 por meio do levantamento secundário e, após a aplicação dos critérios de seleção, apenas 19 artigos foram incluídos nessa revisão. Os autores ${ }^{11}$ concluíram que, comparados aos braquetes convencionais, os autoligados produzem menor fricção quando combinados a arcos redondos de pequeno diâmetro e na ausência angulação e/ou torque, em um arco com alinhamento ideal. Não foram encontradas evidências suficientes para comprovar a baixa fricção de braquetes autoligados em relação aos convencionais, quando do uso de arcos retangulares, na presença de angulação e/ou torque, em casos de má oclusão considerável. A maioria dos estudos avaliados concordam que a fricção de braquetes autoligados e convencionais aumenta com o calibre do arco.

\section{CONSIDERAÇÕES CLÍNICAS E CONCLUSÕES}

Os braquetes autoligados ainda não demonstraram superioridade mecânica em relação aos sistemas convencionais, de forma a justificar seu maior custo. Além disso, a maioria das informações com relação aos sistemas autoligados deriva de material promocional das empresas, relatos de casos e congressos. Em geral, os casos apresentados não são tratados consecutivamente ou selecionados aleatoriamente, portanto não representam a resposta média de uma variedade de casos de pacientes que o clínico encontra no consultório ortodôntico.

Outro importante questionamento levantado nessa breve revisão foi a credibilidade em relação à prescrição do fabricante ${ }^{2}$. Considerando que, ao início do tratamento, escolhemos as prescrições de acordo com o fabricante ou ídolo ortodôntico; em contrapartida, a utilização de fios de aço retangulares ao final do tratamento pode não levar às inclinações desejadas. Se isso de fato não acontece, por que nos preocuparmos tanto com a escolha da prescrição? Acredita-se que o bom senso do profissional será de extrema importância nessa hora, pois todas as prescrições baseiam-se em uma média e nem sempre esse valor médio levará às inclinações desejadas para todos os casos. Mais estudos deverão esclarecer esse quesito, ou simplesmente aceitar que em alguns casos será necessário incorporar dobras de $1^{\mathrm{a}}, 2^{\mathrm{a}}$ e/ou $3^{\mathrm{a}}$ ordens (como preconizado na mecânica Edgewise), no tratamento com a mecânica Straight-wire, para alcançar um bom posicionamento dos dentes na fase da finalização ortodôntica. Ressalta-se, ainda, a importância da avaliação do padrão facial do paciente no momento 
do diagnóstico, pois não há prescrição e nem sistema de braquetes autoligados que compense um padrão facial determinado geneticamente como desfavorável. Secundariamente, o profissional escolhe a técnica (Edgewise ou Straight-wire), prescrição do braquete, tipo (metálico ou estético) e o sistema (autoligado ou convencional), de acordo com a sua preferência pessoal e de cada paciente.

Dessa forma, abraçar o uso dos braquetes autoligados de maneira intempestiva não parece ser a

\section{REFERÊNCIAS}

1. ALPERN, M. C. Gaining control with self-ligation. Semin. Orthod., Philadelphia, v. 14, no. 1, p. 73-86, 2008.

2. ARAÚJO, C. C. M. Avaliação das inclinações dentárias obtidas no tratamento ortodôntico com braquetes autoligáveis utilizando tomografia computadorizada. 2008. 102 f. Dissertação (Mestrado)-Universidade Metodista de São Paulo, São Bernardo do Campo, 2008.

3. BERGER, J. L. Self-ligation in the year 2000. J. Clin. Orthod., Boulder, v. 34, no. 2, p. 74-81, 2000.

4. BERGER, J. L. The clinical efficiency of self-ligating brackets. J. Clin. Orthod., Boulder, v. 35, no. 2, p. 304-408, 2001.

5. BERGER, J. L. The speed appliance: a 14-year update on this unique self-ligating orthodontic mechanism. Am. J. Orthod. Dentofacial Orthop., St. Louis, v. 105, no. 3, p. 217-223, 1994

6. BERGER, J. L. The speed system: an overview of the appliance and clinical performance. Semin. Orthod., Philadelphia, v. 14, no. 1, p. 54-63, 2008.

7. BIRNIE, D. The Damon passive self-ligating appliance system. Semin. Orthod., Philadelphia, v. 14, no. 1, p. 19-35, 2008

8. CLOSS, L. Q. et al. Os diferentes sistemas de braquetes self-ligating: revisão da literatura. Rev. Clin. Ortodon. Dental Press, Maringá, v. 4, n. 2, p. 60-66, 2005.

9. DAMON, D. H. The Damon low-friction bracket: a biologically compatible straigth-wire system. J. Clin. Orthod., Boulder, v. 32 , no. 11 , p. $670-680,1998$.

10. DAMON, D. H. The rationale, evolution and clinical application of the self-ligating bracket. Clin. Orthod. Res., Copenhagen, v. 1 , no. 1, p. 52-61, 1998.

11. EHSANI, S. et al. Frictional resistance in self-ligating orthodontic brackets and conventionally ligated brackets: a systematic review. Angle Orthod., Appleton, v. 79, no. 3, p. 592-601, 2009.

12. HARRADINE, N. The history and development of self-ligating brackets. Semin. Orthod., Philadelphia, v. 14, no. 1, p. 5-18, 2008.

13. HARRADINE, N.; BIRNIE, D. The clinical use of Activa selfligating brackets. Am. J. Orthod. Dentofacial Orthop. St. Louis, v. 109, no. 3, p. 319-328, 1996.

14. KOCHENBORGER, R. Avaliação das alterações dentárias e do perfil facial obtidas no tratamento ortodôntico com braquetes autoligáveis. 2009. 100 f. (Dissertação)Universidade Metodista de São Paulo, São Bernardo do Campo, 2009

15. $L E A L, R$. S. Comparação do atrito in vitro em braquetes metálicos e estéticos convencionais e autoligáveis. 2009. 113 f. Dissertação (Mestrado)-Universidade Metodista de São Paulo, São Bernardo do Campo, 2009. melhor conduta, pois mais estudos com amostras clínicas selecionadas aleatoriamente precisam ser realizados. Esses estudos deveriam abordar a mecânica, bem como as vantagens e desvantagens, de cada sistema, comparando-os entre si e com os braquetes convencionais. Em especial, ainda necessita-se avaliar a estabilidade dos tratamentos com uso de braquetes autoligados, a longo prazo, pois não existe mudança de paradigmas sem evidências científicas.

16. MILES, P. G. Self-ligating vs conventional twin brackets during en-masse space closure with sliding mechanics. Am. J. Orthod. Dentofacial Orthop., St. Louis, v. 132, no. 2, p. 223-225, Aug. 2007.

17. PANDIS, N.; POLYCHRONOPOULOU, A.; ELIADESC, T. Self-ligating vs conventional brackets in the treatment of mandibular crowding: a prospective clinical trial of treatment duration and dental effects. Am. J. Orthod. Dentofacial Orthop., St. Louis, v. 132, no. 2, p. 208-215, Aug. 2007.

18. PELLEGRINI, P. et al. Plaque retention by self-ligating vs elastomeric orthodontic brackets: quantitative comparison of oral bacteria and detection with adenosine triphosphate-driven bioluminescence. Am. J. Orthod. Dentofacial Orthop., St. Louis, v. 135, no. 4, p. 426.e1-426.e9, Apr. 2009.

19. SHIVAPUJA, P. K.; BERGER, J. L. A comparative study of conventional ligation and self-ligation bracket systems. Am. J. Orthod. Dentofacial Orthop., St. Louis, v. 106, no. 5, p. 472-480, Nov. 1994.

20. STOLZENBERG, J. The Russel attachment and its improved advantages. Int. J. Orthod. Dent. Child., [S.I.], v. 21 p. 837-840, 1935.

21. THOMAS, S.; SHERRIFF, M.; BIRNIE, D. A comparative in vitro study of the frictional characteristics of two types of self-ligating brackets and two types of pre-adjusted Edgewise brackets tied with elastomeric ligatures. Eur. J. Orthod., Oxford, v. 20, no. 5, p. 589-596, Oct. 1998.

22. TREVISI, H. SmartClip: tratamento ortodôntico com sistema de aparelho autoligado - conceito e biomecânica. Rio de Janeiro: Elsevier, 2007.

23. TREVISI, H.; BERGSTRAND, F. The SmartClip self-ligating appliance system. Semin. Orthod., Philadelphia, v. 14, no. 1, p. 87-100, 2008.

24. VALANT, J. R. Time: a self-ligating interactive bracket system. Semin. Orthod., Philadelphia, v. 14, no. 1, p. 46-53, 2008

25. WILDMAN, A. J. et al. Round table: the Edgelok bracket. J. Clin. Orthod., Boulder, v. 6, no. 11, p. 613-623, 1972.

\section{Endereço para correspondência}

Renata Castro

UMESP, Faculdade de Odontologia, Pós-Graduação em Ortodontia Rua do Sacramento, 230 / Ed. Lambda - Rudge Ramos

CEP: 09.640-000 - São Bernardo do Campo / SP

E-mail: renata.castro@metodista.br 